Tohoku J. exp. Med., 1983, 140, 53-58

\title{
Effects of Nifedipine on the Renal Vascular Responses and Blood Pressure Responses to Norepinephrine and Angiotensin II in the Anesthetized Rabbit
}

\author{
Sadayoshi Ito, Masahide Seino, Minoru Yasujima, \\ Keishi Abe and Kaoru Yoshinaga \\ Second Department of Internal Medicine, Tohoku University \\ School of Medicine, Sendai 980
}

Ito, S., Seino, M., Yasujima, M., Aвe, K. and Yoshinaga, K. Effects of Nifedipine on the Renal Vascular Responses and Blood Pressure Responses to Norepinephrine and Angiotensin II in the Anesthetized Rabbit. Tohoku J. exp. Med., 1983, 140 (1), 53-58 — Effects of a Ca-antagonist, nifedipine, on renal vascular responses and systemic pressor responses to angiotensin II and norepinephrine were studied in anesthetized rabbits. The changes of renal blood flow were estimated by an electromagnetic flowmeter. After the intravenous administration of nifedipine $(50 \mu \mathrm{g} / \mathrm{kg})$, mean blood pressure decreased from $116 \pm 3.1 \mathrm{mmHg}$ to $102 \pm 3.4 \mathrm{mmHg}(p<0.001)$. Renal vascular responses to angiotensin II were attenuated significantly after the administration of nifedipine, but not changed to norepinephrine. Pressor responses to angiotensin II at a low dose were significantly diminished after the administration of nifedipine $(p<0.05)$, whereas it had no effect at higher doses. Nifedipine tended to suppress the increase in arterial pressure induced by norepinephrine, but the changes were not statistically significant. These results suggest that calcium influx in the vascular smooth muscle cells is not likely to be a common pathway in the vasoconstrictor reaction to angiotensin II and norepinephrine in anesthetized rabbit.— nifedipine; norepinephrine; angiotensin II; blood pressure; renal vascular response

Ca-antagonists are known to dilate coronary arteries and peripheral vessels, and to have negative inotropic effect on the heart (Fleckenstein et al. 1969; Grün and Fleckenstein 1972; Vater et al. 1972). It is thought that the mechanism of the action is mainly a selective inhibition of $\mathrm{Ca}^{++}$influx through the slow channel (Fleckenstein 1977). It has been reported that Ca-antagonists inhibit the vasoconstrictor action of norepinephrine in the isolated aorta and mesenteric artery of the rabbit (Schümann et al. 1975), but gave no effect on the isolated mesenteric artery of the rat (Kondo et al. 1981). Little is known regarding the effect of Ca-antagonists on the changes of systemic blood pressure and renal hemodynamics induced by norepinephrine or angiotensin II. Therefore, in the present study, we investigated the effects of Ca-antagonist on systemic blood pressure and renal vascular responses to norepinephrine and angiotensin II. We

Received for publication, July 24, 1982. 
used nifedipine as a Ca-antagonist, since it is reported that this drug has a higher vascular selectivity than other Ca-antagonists (Narimatsu and Taira 1976).

\section{Methods}

Nine female Japanese rabbits weighing 3.2 to $3.7 \mathrm{~kg}$ were used in this study. All of the rabbits were maintained on a normal chow and water intake ad libitum. Anesthesia was introduced with intravenous administration of urethane $(450 \mathrm{mg} / \mathrm{kg})$ and $\alpha$-chloralose $(45 \mathrm{mg} /$ $\mathrm{kg}$ ), and maintained with periodic additional administration of them. The trachea was cannulated. A catheter (PE-60) was introduced into the abdominal aorta through the femoral artery for blood pressure measurement. Blood pressure was monitored with a pressure transducer and amplifier (Biophysiograph, 180 system, SAN-EI). Another catheter (PE-50) was introduced into the inferior vena cava through the femoral vein for the administration of supplemental anesthetics, norepinephrine, angiotesin II, and nifedipine. The left renal artery was exposed through a left flank incision, and fitted with a flow probe of appropriate diameter (1.5 to $2.0 \mathrm{~mm}$, Niнon KoHDEN). A flow probe was connected to an electromagnetic flowmeter (MF-27, NiHON KoHDEN). Mean arterial pressure and renal blood flow were simultaneously recorded on a pen oscillograph (Type 8k 13, SAN-EI).

After surgery, at least $1 \mathrm{hr}$ was allowed to elapse to stabilize the blood pressure and renal blood flow. Then the dose-response curves to norepinephrine and angiotensin II were obtained. DL-Norepinephrine (SANkYo, $1 \mathrm{mg} / \mathrm{ml}$ ) and angiotensin II (Hypertensin, CIBA, $0.1 \mathrm{mg}$ ) were diluted with $5 \%$ dextrose to appropriate concentrations, and infused intravenously for $3 \mathrm{~min}$ with an infusion pump (HARvard, 940E). The doses used for norepinephrine were $0.25,0.5,1.0$ and $2.5 \mu \mathrm{g} / \mathrm{kg} / \mathrm{min}$ and for angiotensin II were $10,20,50$ and $100 \mathrm{ng} / \mathrm{kg} / \mathrm{min}$. Following the determination of dose-response curves, $50 \mu \mathrm{g}$ per $\mathrm{kg}$ of nifedipine (BAYER, $0.2 \mathrm{mg} / 2 \mathrm{ml}$ ) was administered intravenously. Extreme care was taken to reduce the exposure of nifedipine to light. Fifteen min were allowed for equilibrium period after the administration of nifedipine, then dose-response curves to norepinephrine were obtained again. After that, the additional administration of the same dose of nifedipine was given. Fifteen min later, dose response curves to angiotensin II were obtained. To study the influence of the additional administration of nifedipine on responses to norepinephrine and angiotensin II, dose-response curves to these vasoconstrictors were obtained in the reversed order in three rabbits (first to angiotensin II then to norepinephrine).

Renal vascular resistance was calculated as dividing mean arterial pressure by renal blood flow, and expressed as $\mathrm{mmHg} / \mathrm{ml} / \mathrm{min}$. All values were expressed as mean \pm s.E. Data were analyzed by paired $t$-test.

\section{RESUlts}

In control period, mean arterial pressure was $116 \pm 3.1 \mathrm{mmHg}$, and it remained stable without irregular fluctuations during the determination of doseresponse curves to norepinephrine and angiotensin II. After the first administration of nifedipine, mean arterial pressure fell significantly to $102 \pm 3.4 \mathrm{mmHg}(p<$ $0.001)$. After the additional administration of nifedipine, mean arterial pressure was $98.4 \pm 3.4 \mathrm{mmHg}$, which was significantly lower than that in the control period, but was not significantly different from the mean arterial pressure after the first administration of nifedipine.

Renal blood flow during the control period, after the first administration of nifedipine and after the second were $38.1 \pm 4.6,37.9 \pm 5.9$ and $36.2 \pm 5.3 \mathrm{ml} / \mathrm{min}$, respectively. There were no significant differences among these three values. 
There were no significant differences either in the three basal renal vascular resistances $(3.5 \pm 0.4,3.3 \pm 0.5$ and $3.3 \pm 0.5 \mathrm{mmHg} / \mathrm{ml} / \mathrm{min})$.

Fig. 1a shows the effect of nifedipine on the changes of mean arterial pressure induced by angiotensin II infusion. After the administration of nifedipine, the increase of mean arterial pressure was significantly attenuated from $6.9 \pm 1.1$ to $4.9 \pm 1.2 \mathrm{mmHg}(p<0.05)$ at a dose of $10 \mathrm{ng} / \mathrm{kg} / \mathrm{min}$. However, nifedipine had no significant effect at higher doses of angiotensin II.

Fig. $1 \mathrm{~b}$ shows the effect of nifedipine on the changes of renal blood flow induced by angiotesin II. Nifedipine significantly suppressed the decrease in renal blood flow from the control values of $6.7 \pm 2.0,11.3 \pm 2.8,15.7 \pm 3.3$ and $18.9 \pm 3.5$
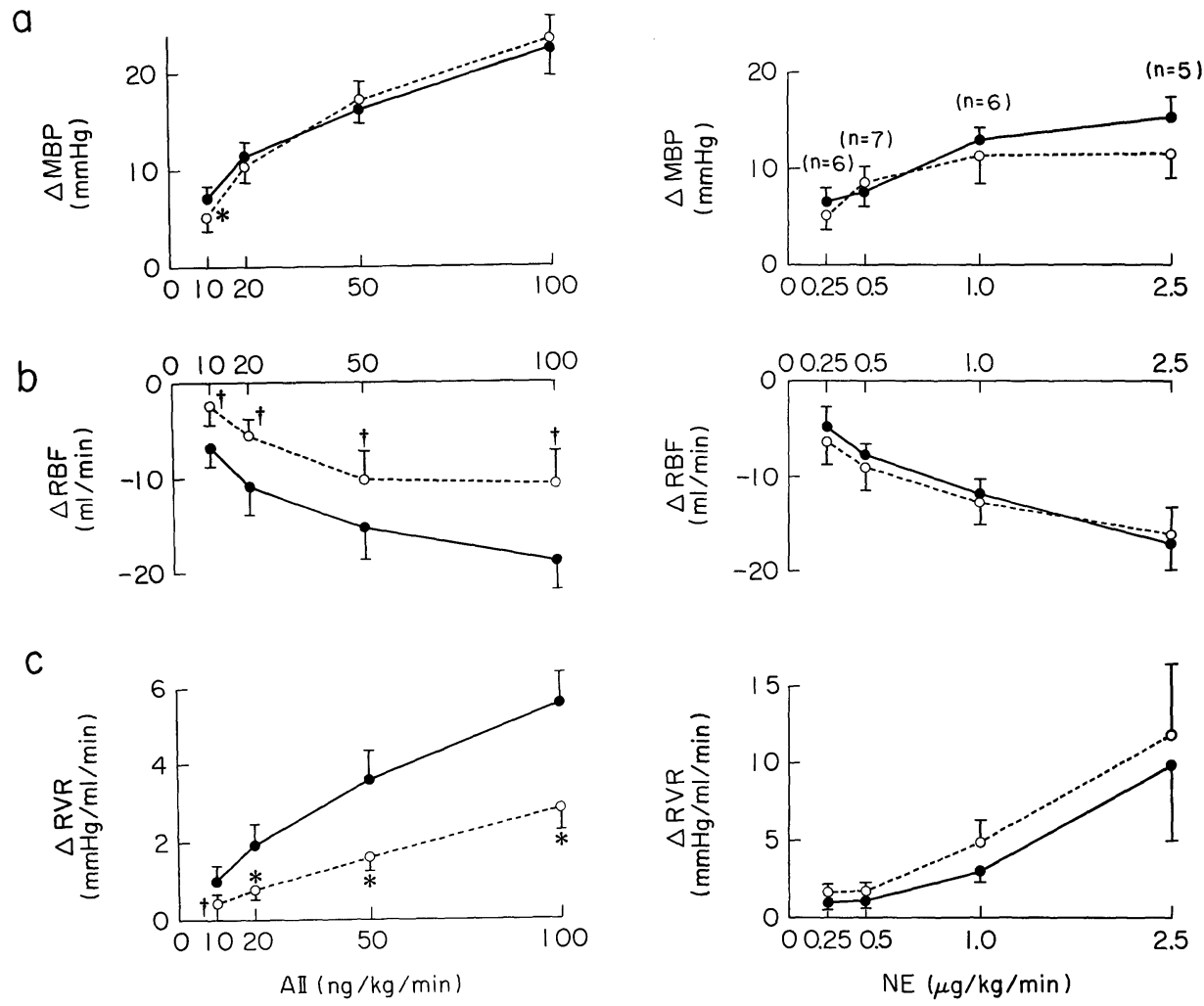

Fig. 1

Fig. 2

Fig. 1. Effects of nifedipine on the vasoconstrictor action of angiotensin II. The changes of mean blood pressure (MBP), renal blood flow (RBF) and renal vascular resistance (RVR). $n=9$.

$-\bullet$, before the administration of nifedipine; $\circ-. \circ$, after the administration of nifedipine. Bars represent the mean \pm s.E. ${ }^{*} p<0.05, \dagger p<0.01$.

Fig. 2. Effects of nifedipine on the vasoconstrictor action of norepinephrine. The changes of mean blood pressure (MBP), renal blood flow (RBF) and renal vascular resistance (RVR).

$\bullet-\bullet$, before the administration of nifedipine; 0 -..०, after the administration of nifedipine. Bars represent the mean \pm s.E. 
$\mathrm{ml} / \mathrm{min}$ to $2.6 \pm 1.6,5.6 \pm 1.9,10.1 \pm 2.9$ and $12.8 \pm 3.5 \mathrm{ml} / \mathrm{min}$, respectively, at each dose of angiotensin II $(p<0.01$, in each value). Fig. 1c shows the effect of nifedipine on the changes of renal vascular resistance. After the administration of nifedipine, the increases in renal vascular resistance induced by angiotensin II infusion were significantly suppressed from $0.9 \pm 0.3,2.0 \pm 0.5 \mathrm{~m} \quad 3.6 \pm 0.9$ and $5.6 \pm 1.2 \mathrm{mmHg} /$ $\mathrm{ml} / \mathrm{min}$ to $0.3 \pm 0.1,0.7 \pm 0.2,1.6 \pm 0.4$ and $2.9 \pm 0.6 \mathrm{mmHg} / \mathrm{ml} / \mathrm{min}$, respectively. All of these changes were statistically significant.

Fig. 2a shows the effect of nifedipine on the changes of arterial pressure induced by norepinephrine infusion. Nifedipine tended to suppress the increase in arterial pressure induced by norepinephrine, though the suppression was not statistically significant. Figs. $2 \mathrm{~b}$ and $\mathrm{c}$ show the effect of nifedipine on the changes of renal blood flow and renal vascular resistance induced by norepinephrine. Nifedipine failed to elicit any significant effects on the responses to norepinephrine.

In some rabbits, severe decrease in renal blood flow was observed during the infusion of norepinephrine. When it was expected that the renal blood flow could not restore to the control level, the infusion of norepinephrine was stopped immediately, and the values were excluded from the statistical analysis.

\section{Discussion}

In the present study, nifedipine attenuated the decrease in renal blood flow and the increase in renal vascular resistance induced by angiotensin II. However, no significant effect of nifedipine was observed on the renal vascular responses to norepinephrine. These results suggest that effect of nifedipine on renal vascular constriction is different in the cases of angiotensin II and of norepinephrine. Nifedipine is commonly believed to interfere with the slow inward current of $\mathrm{Ca}^{++}$ (Fleckenstein 1977), but an effect on intracellular calcium release has also been reported (Church and Zoster 1980). In vitro, nifedipine partially inhibits the vasoconstrictor responses to norepinephrine, and norepinephrine-mediated constriction depends on both extra- and intracellular $\mathrm{Ca}^{++}$(Hudgins and Weiss 1968; Seidel and Bohr 1971; Godfraid and Koba 1972; Meisheri et al. 1980; Walus et al. 1981). In our present study, it is unlikely that transcellular calcium influx is a common pathway for vasoconstrictor action of angiotensin II and norepinephrine in the renal vascular beds. There are also some reports concerning the interaction between Ca-antagonists and vasoconstrictor substances. Yamaguchi et al. (1974) reported that in anesthetized dogs renal arterial administration of another type of Ca-antagonist (diltiazem) exhibited an antagonistic effect on the vasoconstriction of angiotensin II, but had no effect on that of epinephrine. Kondo et al. (1981) observed that nifedipine and diltiazem had no effect on the vasoconstrictor action of norepinephrine in the isolated mesenteric artery of the rat. These two reports are compatible with the observation of our present study. However, Goldberg et al. (1981) showed that the pressor effect of angiotensin II or norepinephrine were markedly attenuated by both nifedipine and verapamil, and that transcellular calcium influx appeared to be a final common pathway for vasoconstrictor 
action of angiotensin II and norepinephrine. It is unclear why these controversial findings are observed. In the present study, nifedipine was administered twice by a bolus injection. It might be argued that the difference between the response to norepinephrine and that to angiotensin II was due to the difference in the dose of nifedipine. Therefore, we tried to infuse angiotensin II and norepinephrine in the reversed order in three rabbits. The responses to norepinephrine after the first administration of nifedipine were the same as responses after the second administration of it. So, it might be thought that there was no influence, at least in the dose of nifedipine used, on norepinephrine response.

In our study, nifedipine significantly diminished the elevation of arterial pressure only at the low dose of angiotensin II $(10 \mathrm{ng} / \mathrm{kg} / \mathrm{min})$, whereas it had no effect at higher doses. It may be due to the difference in the interaction of nifedipine and angiotensin II in various organs, since the change of systemic arterial pressure represents a total vascular response in various organs. Another possibility is that the lack of nifedipine effect may be due to the significant decrease in blood pressure after the administration of nifedipine, since the decrease of blood pressure causes hyperresponse to vasopressor substances.

It has been reported that nifedipine causes renal vasodilatation and the increase in renal blood flow when administered directly into the renal artery (Oguro and Hashimoto 1974). In our study, intravenous administration of nifedipine caused no significant change in renal blood flow or renal vascular resistance. It could be thought that the significant decrease in arterial pressure elicited the release of vasoconstrictors, such as catecholamines or renin-angiotensin. Unfortunately we did not measure these factors. Further, in this study, it was thought that renal circulation was under the autoregulation, because renal blood flow remained unchanged in spite of the significant decrease in blood pressure. The renal autoregulation might not be influenced by the intravenous administration of this dose of nifedipine. However, in the dog, Ono et al. (1974) observed the abolition of autoregulation by nifedipine, when it was infused into the renal artery $(3 \mu \mathrm{g} / \mathrm{min})$ during stepwise increase in perfusion pressure from 100 to 200 $\mathrm{mmHg}$.

In conclusion, nifedipine attenuates the renal vascular responses to angiotensin II, whereas it has no significant effect on the responses to norepinephrine, suggesting that in the renal vascular beds, transcellular calcium influx is not likely to be a common pathway in the vasoconstriction elicited by angiotensin II and norepinephrine.

\section{References}

1) Church, J. \& Zoster, T.T. (1980) Calcium antagonistic drugs. Mechanism of action. Canad. J. Physiol. Pharmacol., 58, 254-264.

2) Fleckenstein, A. (1977) Specific pharmacology of calcium in myocardium, cardiac pacemakers, and vascular smooth muscle. Ann. Rev. Pharmacol. Toxicol., 17, 149-166.

3) Fleckenstein, A., Tritthart, H., Fleckenstein, B., Herbst, A. \& Grün, G. (1969) A new group of competitive Ca-antagonists (Iproveratril, D 600. Prenylamine) with 
highly potent inhibitory effects on excitation-contraction coupling in mammlian myocardium. Pfiügers Arch., 307, R 25.

4) Godfraid, T. \& Koba, A. (1972) The role of calcium in the action of drugs on vascular smooth muscle. Arch int. Pharm. Ther., 196, 35-49.

5) Goldberg, J., Aisenbery, G., Levi, M., Berl, T. \& Schrier, R. (1981) Common pathway for vasoconstrictor properties of angiotensin II, norepinephrine and vasopressin. Kidney int., 19, 167. (Abstract)

6) Grün, G. \& Fleckenstein, A. (1972) Die electromechanische Entkopplung der glatten Gefäßmuskulatur als Grundprinzip der Coronardilatation durch 4(2'-Nitrophenyl)2,6dimethyl-1,4-dihydropyridin-3,5-dicarbonsäure-dimethylester (Bay a 1040, Nifedipine). Arzneimittel Forsch., 22, 334-344.

7) Hudgins, P.M. \& Weiss, G.B. (1968) Differential effects of calcium removal upon vascular smooth muscle contraction induced by norepinephrine, histamine and potassium. J. Pharm. exp. Ther., 159, 91-97.

8) Kondo, K., Ebihara, A., Suzuki, H. \& Saruta, T. (1981) Role of Ca ion on vasoconstriction, angiotensin II, bradykinin and prostaglandin $\mathrm{I}_{2}$ as a mediator. Jap. J. Hypertension, 4, 32. (Japanese)

9) Meisheri, K.D., Hwang, O. \& Van Breeman, C. (1980) Norepinephrine and high$\mathrm{K}^{+}$depolarization utilize separate $\mathrm{Ca}^{++}$channels during vascular smooth muscle activation. Fed. Proc., 39, 711. (Abstract)

10) Narimatsu, A. \& Taira, N. (1976) Effects on atrioventricular conduction of calcium antagonistic coronary vasodilators, local anaesthetics and quinidine injected into the posterior and the anterior septal artery of the atrio-ventricular node preparation of the dog. Arch. Pharmacol., 294, 169-177.

11) Oguro, K. \& Hashimoto, K. (1974) Quantitative and comparative studies of pharmacological features in the coronary, femoral and renal circulations with different coronary vasodilators. Jap. J. Pharmacol., 24, 227-233.

12) Ono, H., Kokubun, H. \& Hashimoto, K. (1974) Abolition by calcium antagonists of the autoregulation of renal blood flow. Naunyn-Schmiedebergs Arch. Pharmacol., 285, 201-207.

13) Schümann, H.J., Görlitz, B.D. \& Wanger, J. (1975) Influence of papaverin, D600, and nifedipine on the effect of noradrenaline and calcium on the isolated aorta and mesenteric artery of the rabbit. Naunyn-Schmiedebergs Arch. Pharmacol., 289, $409-418$.

14) Seidel, C.L. \& Bohr, D.F. (1971) Calcium and vascular smooth muscle. Circulat. Res., 28-29 (Suppl. II), 88-95.

15) Vater, W., Kroneberg, G., Hoffmeister, F., Kaller, H., Meng, K., Oberdorf, A., Puls, W., Schloßmann, K. \& Stoepel, K. (1972) Zur Pharmakologie von 4- (2'-Nitrophenyl)2, 6-dimethyl-1, 4-dihydropyridine-3, 5-dicarbosäure-dimethylester (Nifedipine, Bay a 1040). Arzneimittel-Forsch., 22, 1-14.

16) Walus, K.M., Fondacaro, J.D. \& Jacobson, E.D. (1981) Effects of calcium and its antagonists on the canine mesenteric circulation. Circulat. Res., 48, 692-700.

17) Yamaguchi, I., Ikezawa, K., Takada, T. \& Kiyomoto, A. (1974) Studies on a new 1,5benzothiazepine derivative (CRD-401). Effects on renal blood flow and renal function. Jap. J. Pharmacol., 24, 511-522. 